Carlos Ayala Ramírez

\title{
Responsabilidad ética en el ejercicio del derecho a la información
}

\section{Introducción}

Nadie niega hoy el derecho del ser humano a la información, derecho reconocido en la "Declaración de Derechos Humanos" (Art. 19). El derecho a la información tiene como fundamento la dignidad de la persona y la exigencia del bien común. En efecto, los estados democráticos reconocen formalmente que toda persona tiene derecho a saber, es decir, a ser informado y buscar libremente cualquier información que desee obtener, en particular cuando se refiere a la vida, al trabajo o a las decisiones que hay que adoptar a la vez individualmente y como miembro de la comunidad; liene derecho a transmitir a los demás sus problemas, necesidades y aspiraciones; tiene derecho a discutir las temáticas y problemáticas que influyen en el desarrollo de su vida (Osorio Meléndez, 1997). Pero, la información no se fundamenta sólo en las necesidades individuales o de grupos privados. La sociedad misma, en sus distintos planos, necesila esta información para funcionar adecuadamente. Necesita ciudadanos y ciudadanas bien formados e informados. En otras palabras, los sujetos de este derecho son tanto los individuos como los grupos sociales. Es un derecho no sólo del medio de comunicación o del periodista, sino de la colectividad.

Se reconoce, pues, que el derecho a la información es un derecho fundamental en tanto que en su vigencia o negación se pone en juego parte de la realización humana, y se pone a prueba un factor determinante de lo que constituye una sociedad democrática. Con todo, este derecho aunque es inviolable, no tiene un carácter absoluto. En consecuencia, puede y debe ser reglamentado como lo estipulan de hecho los Tratados y Convenios Intemacionales.

No obstante, nuestro propósito en el presente artículo no es tanto insistir en las normativas jurídicas, sino más bien fundamentar los criterios éticos que deben orientar el hecho humano de la información, tanto en lo que tiene de derecho individual como en su dimensión colectiva. La lectura ética de este derecho conlleva la negación de cualquier intento de restricción o coacción procedente 
de toda forma de poder, pero también nos alerta de las posibles degradaciones o desviaciones que pueden producirse en sus formas concretas de ejercitarlo. La responsabilidad ética no es una condición circunstancial dentro de la labor informativa, es uno de sus pilares fundamentales. Así como la investigación no es una especialidad dentro del mundo periodístico, sino que todo periodismo debe ser investigativo por definición, de igual forma el derecho de informar y comunicar debe estar siempre acompañado de conciencia ética.

\section{2. ¿De dónde surge la necesidad de una ética de la información?}

(a) Los medios de comunicación y el control de la imagen pública. Es evidente que los medios de comunicación social no reducen sus funciones al campo de la información, ni ésta se agota en ellos; sin embargo, existe una notable relación entre medios de comunicación social e información. En efecto, uno de los principales modos que tiene la población para conocer la realidad y tomar posición ante ella, es a través de la imagen pública que proyectan los distintos medios de difusión.

Las tres funciones que suelen caracterizar al periodismo: informar (reflejar la realidad), formar opinión (interpretarla) y la tematización (configuración de una agenda pública) se han convertido en una mediación de hecho entre las diversas instancias de una sociedad y los distintos públicos. Los medios de comunicación, en general, y el periodismo, en particular, son en la actualidad principales impulsadores de la circulación de conocimientos. El ciudadano de la civilización presente convive con ellos y los tiene como punto fundamental de referencia. La gente habla de lo que hablan la televisión, la radio y la prensa e ignora los acontecimientos, sucedidos más allá de un entorno próximo, que no han merecido la calificación de noticiables (De Fontcuberta, 1995). Los medios y los periodistas, en consecuencia, tienen una enorme responsablidad en lo que respecta a la captación y comunicación de la realidad.

(b) Nuevos roles de los medios. Hoy día, los medios masivos de comunicación están acentuando su protagonismo en la sociedad. Para algunos autores (López Vigil, 1997) esta preponderancia se visualiza en por lo menos tres nuevos roles que van adquiriendo en la aclualidad:

Primero, los medios de comunicación legitiman lo que transmiten, es decir, garantizan la autenticidad de algo o alguien. Los medios avalan hechos, situaciones, opiniones o personas. El público cada vez les va olorgando mayor credibilidad, por eso lo que sacan a luz pública, al sonido público, queda valorado. De ahí que se llega a afirmar que lo que sale en los medios vale.

Segundo, los medios establecen la realidad, esto es, no sólo dan a conocer lo que sucede, sino que deciden, establecen la agenda de lo que es importante. Lo que no sale en la pantalla, radio o prensa escrita, simplemente no ha pasado. 
Ellos son también protagonistas de lo que se ha denominado la escena política: los medios eligen los actores (asignando papeles, quién es el protagonista y quién el antagonista); escriben el argumento (fijando la agenda, qué se informa y sobre qué se opina); y provocan el desenlace (conformando la opinión pública). Este rol se puede resumir con la siguiente frase: sólo lo que sale existe.

Tercero, los medios representan a los ciudadanos. Los comunicólogos y periodistas ya no sólo hablan al público, sino en nombre del público. Como representantes de la ciudadanía, los medios se convierten en mediadores entre ésta (la ciudadanía) y el poder. Se conocen casos en el que los medios han destapado escándalos, fiscalizan a las autoridades, defienden los derechos del consumidor y resuelven problemas colidianos del ciudadano común. Claro está que estas afirmaciones hay que matizarlas en cada situación concreta. No obstante, con ellas se busca sustentar un hecho sobresaliente de las sociedades actuales: la centralidad que van adquiriendo los medios masivos. De esta centralidad, configuradora de buena parte de la vida social, se han de derivar importantes exigencias éticas.

(c) El valor-información está afectado por lo esquizofrenio axiológica neoliberal. El teólogo español José Ignacio González Faus (González Faus, 1995), sostiene la tesis de que el neoliberalismo adolece de una gran contradicción ética: son liberales en el terreno económico y neoconservadores en el terreno político-cultural.

Para el mundo económico se propugna la rentabilidad, la eficacia, el poder de convicción, la disciplina laboral; mientras que para el mundo político-cultural se propone la solidaridad, la moderación, la participación, el bien común. En otras palabras, el mundo de la producción ha de estar regido por el individualismo, la ilimitación y el "lodo es experimentable"; mientras que en la convivencia sociopolítica ha de prevalecer la austeridad, la piedad y los límites a la experimentación. A la hora de producir rigen la ley del deseo y la libertad sin límites. Pero a la hora de convivir, se debe controlar el deseo y poner límiles a la libertad.

Esta esquizofrenia axiológica, según Faus, se manifiesta en la forma cómo funcionan algunos valores concretos, por ejemplo, el valor-información. El derecho a la información será un valor en los campos político-culturales de la vida, pero no lo es en el campo económico. En lo que toca al campo político cultural estamos sobre informados, pero en las áreas económicas la información es más escasa y se procura controlarla al máximo. Ocurte también que se suele informar sobre los éxitos macroeconómicos producidos por las medidas neoliberales; pero no se informa de los precios humanos (y medio ambientales) que ha habido que pagar para alcanzar tales logros. Proclamar un logro sin decir su precio distorsiona seriamente la información, porque convierte en un éxito lo que, a lo mejor, no era más que una crueldad. Esta incoherencia axiológica del valor-información, 
cometida en un sistema que pretende hacer de la libertad de información uno de sus valores supremos, plantea la necesidad de una crítica ética que por un lado desmonte la contradicción y, por otro, busque la armonía de valores en el campo informativo.

(d) La lucha entre el afán de lucro y el deber de informar. La prensa predominante (escrita, televisiva y radiofónica) suele estar sustentada en dos ejes principales: por un lado, un alto nivel de competencia empresarial y, por otro, una fuerte vinculación con los sectores de poder político. Ambos aspectos les permite incidir de manera preponderante en el flujo informativo, tener una polente capacidad de difusión, acceder al olorgamiento de exclusivas y estar a la vanguardia de las nuevas tecnologías. No obstante, su participación en el mercado y la consecuente influencia de la economía publicitaria sobre los contenidos informativos, colleva el peligro de que la estrategia de markenting termine decidiendo qué y cómo deben informar los medios de comunicación. Esto deriva en graves limitantes: trivialización de realidad (lo noticiable es lo vendible), orientación hacia un periodismo sensacionalista, pérdida del sentido de contexto en la noticia, predominio de lo instántaneo sobre lo importante, de lo coyuntural sobre lo estructural de la realidad. La participación de los medios de comunicación en el mercado plantea un serio desafío a la ética de la información: la economía publicitaria, ¿factor de posibilidad informativa o amenaza para la libertad de información? (Rub-Mohl, 1995).

(e) Los controles antidemocráticos y la impunidad periodística. La transición del poder ejercido como dominación-exclusión al poder ejercido como participación-concertación, no está exento de trabas y peligros. En el campo de la libre expresión, por ejemplo, se suele recurrir a leyes que limitan la libertad de información. Un caso de esta amenaza lo representa el Nuevo Código Procesal de El Salvador, que incluye disposiciones que cierran el acceso de los periodistas a ciertas fases de los procesos judiciales. El argumento principal para tal medida es la presunción de inocencia de los imputados. El control se torna antidemocrático ya que el dejar a la subjetiva discreción de los jueces la aplicación de reserva para ciertos juicios, se podría estar ocultando información de interés público. Pero, no menos cierto es también el caso contrapuesto: en nombre de una irrestricta libertad de información se puede caer en la impunidad informativa. Impunidad que deriva en encubrimiento, desinformación y daño al honor, al respeto y a la dignidad de las personas. En ambos casos se constata la urgencia de criterios éticos que garanticen, por un lado, el recto ejercicio del derecho a la información y, por otro, que aseguren la libertad de prensa con responsabilidad.

(f) La cultura mediática y su apariencia de una amplia gama de opciones. Vivimos la ilusión de la multiplicidad de medios y espacios comunicativos como una ilusión de la multiplicación de gentes que aparecen en ellos. Parece ser que todos podemos hacemos visibles (García Raya, 1998). Parece ser que la presen- 
cia de los medios masivos y de las redes tecnológicas de información posibilitan suficiente conocimiento de la realidad. Hoy día creemos que podemos saberlo casi todo y saberlo instantáneamente. No obstante, la dimensión ética de este fenómeno presenta al menos dos problemáticas: primero, ¿no seremos simples consumidores, mientras que los controladores del discurso público son cada vez menos con la apariencia de una amplia gama de opciones? (Mata, 1995). Segundo, ¿es suficiente la visibilidad de un determinado sector social o hay que indagar sobre el tipo de imagen pública que se construye en tomo a esos grupos?

\section{Criterios básicos para hablar de una ética de la información}

Planteadas algunas de las realidades que exigen una ética de la información, veamos ahora qué criterios son fundamentales para orientar este hecho humano. Los criterios que aquí enunciaremos y explicaremos no tienen un carácter abstracto y genérico; parten -eso sí- de la realidad concreta y de lo que plantea la ética en este campo. Asimismo, pretenden dar una visión crítica de aquellos aspectos controvertibles del ejercicio de prensa, así como cultivar una praxis responsable de este derecho.

(a) El derecho a la información al igual que cualquier otro derecho básico, debe ser historizado. La historización de los derechos, en este caso el derecho a la información, se constituye en un criterio ético en cuanto que en su aplicación puede determinarse la verdad o falsedad, lo justo o injusto del ejercicio del mismo. La historización consiste en: la verificación práxica de la verdad-falsedad, justicia-injusticia, ajuste-desajuste que se da del derecho proclamado; en la constatación de si el derecho proclamado sirve para la seguridad de unos pocos y deja de ser efectivo para los demás; en el examen de las condiciones reales, sin las cuales no tienen posibilidad de realidad los propósitos intencionales; en la desideologización de los planteamientos idealistas, que en vez de animar a los cambios sustanciales se convierten en obstáculos de los mismos; en la introducción de la dimensión tiempo para poder cuantificar y verificar cuándo las proclamaciones ideales se pueden convertir en realidades o alcanzar, al menos, cierto grado aceptable de realización (Ellacuría, 1990).

La historización nos permitirá, por tanto, evilar una concepción ética puramente abstracta y ahistórica del citado derecho, conducente a reducir la libertad de prensa a un sólo ámbito: la universalidad sin concreción, que termina encubriendo la práctica desigual de un derecho que se ha convertido en privilegio de pocos.

(b) El derecho a la información no es sólo un derecho individual, sino una verdadera exigencia del bien común. Los sujetos de este derecho son tanto los individuos como los grupos sociales, los informadores y los perceptores. Es la sociedad como totalidad la que necesita estar bien informada y eso pasa por asegurar una prensa libre, responsable y objetiva. Pasa por garantizar el acceso de los medios a las fuentes de información y el acceso de los ciudadanos comu- 
nes a los medios. Dos de los diez principios básicos del Nuevo Código Internacional de Etica periodística (López Forero y González Alvarez, 1990), plantean, en este sentido, la responsabilidad social del periodista y el acceso y participación del público.

En cuanto al primer aspecto se establece que la información ha de comprenderse como un bien social, y no como un simple producto, menos como un producto comercial. El periodista es, por tanto, responsable no sólo frente a los propietarios del medio de comunicación, sino, en último término, frente al gran público, lomando en cuenta la diversidad de los intereses sociales. Precisamente, la responsabilidad social del periodista requiere que éste aclúe en todas las circunstancias en conformidad con su propia conciencia ética.

Respecto al segundo principio, se considera que en virtud del carácter mismo de la profesión periodística, se debe favorecer el acceso del público a la información y la participación en los medios, lo cual incluye la obligación de la corrección o la rectificación y el derecho de respuesta.

De este primer criterio deducimos al menos dos consecuencias importantes: primero, el derecho a la información (en cuanto búsqueda y difusión de las noticias), es fundamental para la convivencia y la realización humana, cuyo fin es la consecución del bien común, esto es, del conjunto de bienes naturales, económicos, sociales, políticos y culturales a los que deben tener acceso el mayor número de personas, para posibilitar su desarrollo humano integral. Segundo, el derecho a la información no es exclusivo de los periodistas, de los propielarios de los medios o de grupos de poder. Es también un derecho que los ciudadanos comunes deben ejercer.

Estos dos aspectos son suficientes para fundamentar la necesidad de un equilibrio entre el papel exageradamente protagónico que desempeñan los emisores y los sectores de poder (cuya opinión suele predominar y dominar en la mayoría de medios de comunicación), y la opinión ciudadana que si bien no está del lodo vetada, su presencia e incidencia es mínima en la configuración de la conciencia colectiva. "Cuándo vamos a oír a los hombres y mujeres cotidianos hablar largo y tendido, y con buen conocimiento de causa, sobre los problemas de seguridad, salud, vivienda, educación, recreación, etc., que a diario viven en los diferentes lugares del país? Tal como ahora funcionan los medios parece que nunca. ¿Cuándo vamos a oír —que no sea en programas secundarios y de relleno- a médicos, psicólogos, psiquiatras, sacerdotes, pastores, artistas, sociólogos, intelectuales, antropólogos, pedagogos, trabajadores sociales, odontólogos, y tantos otros especialistas de la realidad, abordar desde sus saberes los problemas del país? Tal como ahora van las cosas, también parece que nunca. ¿Cuándo vamos a salir de una aberración tamaña como creer que la cohorte política es la única llamada a hablar de todo, y por todos?" (Escobar, 1998). El principo ético de que la información es un bien social demanda mayor equidad, en el acceso a los espacios, 
entre emisores y perceptores. Asimismo, el periodista tiene que entender que él no es el protagonista principal de los acontecimientos (ha de superarse el vedetismo y el divismo periodístico), su rol debe ser abrir espacios al ciudadano común, a la comunidad.

Por otra parte, si el derecho a la información ha de estar orientado por las exigencias del bien común, éste no puede estar subordinado, por ejemplo, a la Iógica del mercado y sus intereses como suele ocurrir en la mayoría de medios, por mucho que de allí derive el financiamiento del quehacer informativo. Tampoco puede quedar al arbitrio de la sola voluntad del emisor. Enfatizamos este aspecto porque hoy día asistimos a una creciente influencia de la economía publicitaria sobre qué y cómo informar. En la prática esta influencia termina anulando la necesidad de liberar los flujos infomativos (menor pluralidad de fuentes); se cierra la posibilidad de que todos los aclores sociales ejerzan su derecho a informar e informarse (se reduce el acceso a canales y espacios); se desfavorece el desarrollo de una conciencia colectiva crítica, responsable y creadora (el perceptor se concibe como un mero consumidor de cosas e ideas); la verdad y objetividad informativa es sustituida por la rentabilidad y el marketing (el sencionalismo y el morbo desplazan al afán de verdad); las agendas informativas se construyen a partir de la presión de la competencia (empobrecimiento de los contenidos informativos). En suma, la lógica del mercado termina desnaturalizando el derecho a la información como exigencia del bien común.

(c) El derecho a la información tiene que estar ajustado con la verdad y con la honradez hacia la realidad. Hoy día, algunos gremios periodísticos (por ejemplo, la Sociedad Interamericana de Periodistas, SIP) consideran que la exigencia ética de informar verazmente, puede constituirse en una especie de censura y control a la prensa. Bajo el pretexto de que los gobemantes pueden manipular el principio de la información veraz, esto es, utilizarlo como instrumento de restricción, y asumiendo acríticamente que la verdad objetiva no existe, estos defensores de la libertad informativa proponen la anulación total de cualquier tipo de nomativas, incluyendo el principio ético de la veracidad y la objetividad. Ante esta pretendida libertad absoluta, hay que recordar que toda libertad humana es una libertad concreta y situada, condicionada en muchísimos aspectos (naturales, sociales, políticos, éticos, etc.). Por eso todo tipo de libertad humana (para el caso la libertad de prensa) hay que plantearla en el marco de esos condicionamientos y en el marco de la interacción ser humano-mundo.

La búsqueda y la comunicación de la verdad se torna no sólo en un criterio ético fundamental, sino a su vez urgente, por cuanto la realidad está configurada por la mentira y el encubrimiento. "Nunca ha habido tantas posibilidades para conocer la verdad, tantos centros de investigación y difusión del conocimiento y, sin embargo, en nuestro mundo existe una ignorancia escalofriante de la realidad fundamental de la humanidad. El ciudadano medio no parece tener conocimiento 
cabal de lo mal que está la totalidad de nuestro mundo, ni parece tener interés por superar ese desconocimiento (...) Hay otros modos sutiles de encubrir la verdad, lo que suele ocurrir en los medios, en los discursos de políticos, gobernantes, militares, y puede ocurrir también en discursos de intelectuales y eclesiáticos (...), se usan eufemismos: países en 'vías de desarrollo', 'democracias incipientes'. Se usa el chantaje: decir la verdad pondría en peligro la estabilidad política, los bienes alcanzados (...) Se informa de manera absolutamente desproporcionada: minutos para la catástrofe humana en Sudán; centenares y miles de horas para Francia 98. Se introyecta el olvido: ¿quién habla de EI Salvador, Nicaragua, la Escuela de Las Américas, los contras y el Irangate, el asesinato de Monseñor Romero? (...) Y hasła la libertad de expresión puede ser usada para minimizar o anular la verdad: se ofrecen tantas noticias que se diluye la realidad principal; se ofrecen tantas y tan diversas interpretaciones de un mismo hecho que éstas se balancean y anulan eficazmente una a otra, y la realidad más honda permanece oculta. Y lo fundamental: más libertad tiene para expresarse el que tiene más poder económico" (Sobrino, 1998).

A lo señalado arriba hay que agregar otras desviaciones en el ejercicio de la información, que han minado la posibilidad de superar la mentira y el encubrimiento: unas derivadas de una mala conceptuación en lo que respecta a la objetividad y la verdad en la noticia. Hay quienes piensan que la objetividad es sinónimo de neutralidad valorativa, entendida ésta como la separación entre juicio de hecho y juicio de valor, y la prohibición de todo juicio crítico sobre la realidad. La neutralidad axiológica pretende ocultar el hecho de que la ideología del propio medio o del periodista interviene en su peculiar modo de escoger, interpretar y difundir una determinada noticia.

Otras desviaciones son producidas por la forma cómo se aborda la información (Vidal, 1980). Ejemplos: La presentación parcial de una verdad (consiste en ocultar deliberadamente aquellos aspectos de la realidad que pueden permitir a la población aprehender la totalidad de los hechos de forma que pueda emitir un juicio crítico, libre y completo); el sensacionalismo (consiste en distorsionar los hechos mediente la acentuación de aquellos aspectos que provocan reacciones emocionales, no racionales); los silencios (suprimir determinadas informaciones cuyo conocimiento pondría en duda o al descubierto intereses inconfesables); dar carácter objetivo a lo que sólo tiene un valor subjetivo y relativo (mezclar noticias y su interpretación ideológica, presentando ésta última como parte de los hechos); la generalización de hechos parciales (generalizar abusivamente un hecho que por sus características y naturaleza es individual).

Frente a estas desviaciones, desde la ética se exige una mayor objelividad en la selección y jerarquización de las informaciones. Pero, ¿en qué consiste la objetividad informativa? La objetividad consiste en lograr reproducir, como objeto teórico-informativo, el hecho noticioso con loda su complejidad. La objeti- 
vidad así entendida requiere un gran esfuerzo de racionalidad y criticidad. Esfuerzo que supone: mantenerse fiel a los hechos, no hay que abultar las cifras ni exagerar los datos, decir lo que no es ni dejar decir lo que es; comprobar los hechos, asegurar la exactitud de los datos, que estén bien confirmados; distinguir entre informar y opinar, la noticia no debe arroparse con comentarios o matices editorializantes; recurrir a la orra versión, cuando el hecho es complejo el pluralismo de fuentes es condición necesaria para lograr objetividad (López Vigil, 1997).

En otras palabras, se requiere un distanciamiento crítico que distinga lo que es información de lo que es opinión, lo que es difusión de lo que es propaganda, lo que es nacional de lo que es partidista. Evitar el socorrido artificio de atribuir a sectores no debidamente acreditados las opiniones del propio medio, no generalizar lo particular y no deformar el peso específico de cada información (Ellacuría, 1989).

Ante el mal manejo de los recursos económicos públicos, la demagogia y la mentira política, ante el crecimiento de la impunidad y la existencia de leyes injustas, ante el creciente empobrecimiento de las mayorías, ante el abuso y daño del ecosistema, ante la manipulación de la conciencia colectiva y personal, ante la discriminación a causa del sexo, raza o edad, en suma, ante un deterioro creciente de la dignidad humana, se exige fidelidad a la verdad y honradez con la realidad. Se trata de buscar y decir la verdad y erradicar la mentira y el encubrimiento (Sobrino, 1993).

Sobre este tema el Nuevo Código Internacional de Etica Periodística, que hemos tomado como punto de referencia, expresa que el pueblo y las personas tienen el derecho a recibir una imagen objetiva de la realidad por medio de una información precisa y completa (CIEP, No. 1). Agrega además, que la tarea primordial del periodista es la de servir a una información verídica y auténtica por la adhesión honesta a la realidad objetiva, siluando conscientemente los hechos en su contexto adecuado, manifestando sus relaciones esenciales y empleando toda la capacidad creativa del profesional (CIEP, No. 2).

(d) El derecho a la información supone competencia y responsabilidad en la emisión y la recepción de la noticia. Por lo que respecta a los periodistas en cuanto formadores de opinión, deben esforzarse en conseguir mayor capacitación profesional, mayor independencia ante las diversas presiones y mayor investigación sobre los grandes problemas de la realidad.

La capacilación es necesaria para poder cumplir adecuadamente con una de las misiones que la colectividad espera de ellos, esto es, captar plena y objetivamente la realidad y comunicar esa caplación de la mejor forma posible.

Para que la labor informativa sea creadora y crítica ha de tener como condición básica la independencia. Independiente de los intereses partidaristas, frente 
a la propia empresa de comunicación cuando ésta coarta la libertad de información y de expresión del periodista, independiente frente a la presiones del gobiemo y de la empresa privada, crítico frente a la propia ideología.

Toda actividad periodística es por definición invesligativa, no obstante, la agenda noticiosa sigue dominada por fuentes oficiosas en menoscabo de la investigación que pueda dar cuenta en toda su complejidad de los acontecimientos más importantes de la realidad. Se difunde más lo que dan las fuentes oficiosas que lo relacionado a los intereses de la nación considerada como un todo. Se pone énfasis en la coyuntura y no en la memoria histórica. Se da mayor protagonismo a las personalidades y se minimiza la opinión del ciudadano común.

En este mismo marco hay que plantear el conflicto que suele darse entre la libertad de información, por una parte, y el derecho a la intimidad, la privacidad y la honra, por otra. Ya hemos señalado que la libertad de prensa no es un derecho absoluto. Pero tampoco el derecho a la intimidad y a la privacidad son derechos absolutos. Ambos tienen sus límites y están marcados por los siguientes factores (Pérez, 1998): en primer lugar, el inserés público (ligado al bien común), que no ha de confundirse con la curiosidad pública; en segundo lugar, el daño eventual a terceros inocentes, dado que a la ética no le es lícilo permitir que los inocentes sufran por causa de una conducta ajena mantenida oculta o en silencio, lo cual sería una complicidad; en tercer lugar, el consentimiento otorgado por las personas concernidas para que se publiquen sus asuntos íntimos o privados, pero aún con el consentimiento de las personas, el informador responsable debe saber discernir si realmente esas revelaciones permilidas son de verdadero interés para el bien del público al que se informa (peligro del sensacionalismo); finalmente, otro factor limitante es el que corresponde al carácter público de las personas implicadas, en la medida en que una persona desempeña funciones públicas, el círculo de su vida privada se torna cada vez más reducido, por eso el que los informadores traten de conocer lo más posible a las personas públicas es éticamente válido y justificable.

Similares criterios pueden seguirse en relación con las actitudes de los perceptores. La dimensión ética de la información demandaría de ellos mayor capacilación para interpretar lo que recibe de los medios. Exigiría lucidez crítica para deteclar los intereses ocultos que se esconden tras la apariencia de información. Exigiría, si la verdad está oprimida, comprometerse en la lucha contra la mentira (buscar y decir la verdad). En olras palabras, del perceptor se espera una actitud activa que lo conduzca a saber pensar (sólo piensan lo mismo los que no piensan), a pasar de la ignorancia al saber (los estudios y la investigación son condiciones para ello), a pasar de la mentira a la verdad (construir sobre la verdad que libera y humaniza).

(e) El derecho a la información demanda un lenguaje que descubra y no encubra la realidad de las mayorías pobres. La realidad de las mayoría pobres 
suele ser escándalo para los que pretenden vender la situación latinoamericana como una sociedad democrática. Por eso, a través de la información se la puede dulcificar y encubrir y parte de ese encubrimiento se lleva a cabo por medio del lenguaje. Para hablar de los pueblos pobres se recurre a eufemismos: "cuarto mundo", "el sur", "países en vías de desarrollo", etc. Con esto se quiere decir que algo anda mal, pero estos lenguajes no comunican todo lo mal que anda el mundo (Sobrino, 1998). Jon Sobrino propone, en este sentido, la metáfora del "pueblo crucificado". Este término - afima- expresa muerte, y muerte es la realidad a la que están sometidos los pueblos, de forma lenta y cotidiana a causa de la miseria (violencia institucionalizada), a causa de represión y guerras, a causa de la muerte de la identidad (pérdida de culturas propias).

La información mediatizada por un determinado uso del lenguaje, puede conducir a una visión de la realidad alomizada y sin contexio, ocultadora del drama de la injusticia estructural. De ahí que el presente criterio élico nos advierte de la necesidad de un distanciamiento crílico con respeclo al lenguaje que usamos para comunicar la realidad: lenguaje encubridor o desvelador. La opción ética, claro está, es descubrir la realidad con todo lo que tiene de tragedia y escándalo, de injusticia y de mentira institucionalizada.

(f) En un sistema democrótica, el derecho a la información supone acceso a las fuentes por parte de los informadores, libre circulación de las noticias y receptividad activa por parte del público. La compatibilidad entre información y democracia supone la posibilidad real de acceso a las fuentes, los canales y espacios, la igualdad de oportunidades y la pluralidad de flujos informativos. En las sociedades autoritarias existe un control y sobordinación de los medios a los intereses de los grupos de poder. En las sociedades con pretensiones democráticas se enfatiza la autonomía de los medios con respeclo a esos grupos.

La democracia fortalece el ejercicio de libre expresión e información y éstas últimas actualizan dos valores fundamentales de la democracia. Allí donde el autoritarismo concentra el poder político, a los comunicadores no les queda más remedio que volverse "voz oficial". Y cuando la información es monopolizada por el Estado o por un grupo privilegiado, ésta se reduce a un mero ejercicio de publicidad. Sólo en el marco de una comunicación democrática, los medios producen públicos bien informados; se convierten en instancias mediadoras entre el poder público y la comunidad; se abre el pluralismo de opiniones y de medios.

La compatibilidad entre información y democracia supone también la existencia de una opinión pública realmente pública. Es decir, se supera el hecho de presentar como opinión pública lo que es simplemente opinión interesada o vender como sentir colectivo lo que no pasa de ser una visión muy particular. La opinión pública cuando es realmente tal, nace de dos fuentes: por un lado, de las personas con su potencial de conocer y discemir, y, por el otro, de los flujos de información a los que ellas están expuestas. 
Pero, para que la información sirva de base a una opinión pública se requiere: que la información sea producida y transmitida sin cortapisas (sin censura previa); que nadie sea excluido del derecho a la información; que exista una diversidad de medios y canales de transmisión que rompan la información sesgada o la limitada oferta de los monopolios comunicacionales, y la presencia de públicos con capacidad de recepción e interpretación de la información disponible (Brunner Ried, 1996).

(g) Desde la ética y la racionalidad se exigiria que el derecho a la información favoreciera aquellos procesos orientados al establecimiento de una democracia real. Hay que reiterar que, según lo estipula el Nuevo Código Internacional de Etica Periodística, éste (el periodista) debe, por un lado, defender los valores universales del humanismo, en particular la paz, la democracia, los derechos del hombre, el progreso social y la liberación nacional. Por otro lado, debe participar activamente en las transformaciones sociales orientadas hacia una mejora democrática de la sociedad, de forma que favorezca la paz, la justicia y la distensión (CIEP No. 8).

En este sentido, algunos procesos que deben ser potenciados, desde el derecho a la información, son los siguientes: frente a la precariedad de la vida humana por las que suelen pasar las mayorías, se debe posibilitar y comunicar la justicia social, la solidaridad con los más débiles, la honradez, la austeridad, el bien común y los derechos sociales que salvaguarden la vida; frente al fomento del individualismo, la pasividad y el olvido, hay que desarrollar una conciencia personal y colectiva situada, responsable y solidaria; frente a los modelos políti$\cos$, económicos y culturales, que no responden a la realidad propia, hay que fomentar la memoria histórica en lo que tiene de pasado, presente y de posibilidades futuras.

\section{Conclusión}

Es lugar común reconocer que toda sociedad con pretensiones democráticas tiene que asegurar, entre otras cosas, la libertad de expresión y el derecho a la información. Desde la perspectiva ética la salvaguarda de estas libertades implica: fortalecer un periodismo libre, independiente, responsable y pluralista; defender permanentemente estos principios de cualquier restricción o coacción procedente de toda forma de poder; estar vigilantes de cualquier posible desviación o degradación producida por un mal ejercicio del derecho por parte de los propios medios o de quienes trabajan en ellos; permitir al ciudadano común expresar sus propias opiniones; someter a un examen continuo y crítico el ejercicio de los distintos poderes; respetar el derecho del público a ser informado verazmente sobre hechos y acontecimientos; rectificar todas las informaciones entregadas o publicadas que posteriormente resulten ser falsas; presentar las informaciones, los comentarios y la crítica evitando la intromisión injustificada en la vida priva- 
da, la difamación y las acusaciones sin fundamento; evitar el fomento de la violencia, el odio, la intolerancia o cualquier tipo de discriminación. Garantizar estos principios es responsabilidad ética no sólo de los periodistas, sino de todos los ciudadanos.

Dicho más concretamente, ante el hecho, bastante constatable, del control de la imagen pública que se ejerce a través del vínculo medios de comunicación social-información, la élica y la racionalidad exigen que ésta (la información) esté ajustada con la verdad y con la honradez hacia la realidad.

Frente al nuevo rol de los medios y del periodismo (legitiman, establecen lo que es real, representan a los ciudadanos), la ética recalca la necesidad de historizar tales roles para verificar si lo que se legitima (hechos, personas o situaciones) está ajustado o desajustado con la verdad; si lo que se presenta como "la realidad" tiene sustento en lo real o es pura apariencia; si la representación que tienen o pretenden tener es posibilitadora de participación ciudadana o sustitutiva de la misma.

Ante la aparente sobreinformación en unos campos y el control y escasez en otros, la ética y la racionalidad nos lleva a preguntamos: ¿quiénes arman o diseñan las variadas o repetidas programaciones enlre las que podemos elegir? ¿Quiénes construyen las agendas informativas que se reileran en periódicos y noticieros? ¿Quiénes escogen y determinan los sujetos que obtienen espacios en los medios? ¿Quiénes hacen las preguntas? ¿Quiénes deciden enfocar cierlos rostros y dejar en la penumbra a otros? Si se responde con rigor a estas preguntas constataremos, por un lado, que la idea de abundancia informativa no es tal, y por otro, que asistimos a un creciente control del discurso público bajo la máscara de una cada vez más amplia gama de opciones (Mata, 1995).

Frente a la creciente influencia de la economía publicitaria sobre los contenidos informativos, que puede llevar a una exacerbación desproporcionada del interés, por ideas y hechos (sensacionalismo o información orientada a alimentar los sentimientos morbosos o la curiosidad malsana de los ciudadanos), la ética enfatiza la finalidad social de la información. Esto es: se informa para formar opinión (generar o impulsar corrientes de opinión favorables a los intereses legítimos de las mayorías); se informa para inconformar (sensibilizar sobre los problemas más importantes y mover voluntades para resolverlos); se informa para iransformar, para crear consensos sociales en tomo a proyectos democráticos y causas nobles, para salir del conformismo y la indiferencia colectiva (López Vigil, 1997).

Ante los encubrimientos (implíticos y explícilos), la presentación parcial de una verdad, los silencios, la manipulación del pasado, el olvido o la mentira sin más; la ética y la racionalidad exigen una posición crílica y un afán por buscar y comunicar la verdad con toda su concreción. En la ética periodística se besan el respeto por la verdad y el servicio al bien común. Más aún, en determinadas 
circunstancias históricas, el mayor servicio que se puede prestar a la comunidad es transmitirle la verdad.

\section{Referencias bibliográficas}

Brunner, Ried, José Joaquín, "Comunicación y política en la sociedad democrática", $M e$ dios de comunicación en tiempos de cambio, Fundación Konrad Adenauer, Buenos Aires, Argentina, 1996, pp. 7-18.

De Fontcuberta, Mar, La noticia, pistas para percibir el mundo, Barcelona: Edilorial Paidós, 1995.

Ellacuría, Ignacio, "El periodismo salvadoreño ante la crisis del país", San Salvador (mimeo), 1989.

Ellacuria, Ignacio, "Hislorización de los derechos humanos desde los pueblos oprimidos y las mayorías populares", Estudios Centroamericanos (ECA), 502, 1990, pp. 589596.

Escobar, Francisco Andrés, "La rueda de caballitos", Orientación, Organo oficioso del Arzobispado, San Salvador, 4 de octubre, 1998, p. 16.

García Raya, María Eugenia, "Comunicación política y organizaciones sociales", Signo y Pensamiento, No. 32, Universidad Javeriana de comunicación, Bogolá, 1998, pp. 8390.

González Faus, José Ignacio, "Conflicto de valores en la dispusa en rorno al Neoliberalismo", en Cristianisme i Jusfícia. El neoliberalismo en cuestión, Sal Terrae, Barcelona, 1993, pp. 149-173.

López Forero, Luis y González Alvarez, Luis José, Etica, comunicación y códigos del periodismo, Bogolá: Editorial El Buho, 1990.

Lopéz Vigil, José Ignacio, Radialistas apasionados, Artes Gráficas SILVA, Quito, 1997.

Mala, María Cristina, El derecho a la comunicación, San Salvador (mimeo), 1995.

Osorio Meléndez, Hugo, Políticas de Información y derecho, Fundación Konrad Adenauer, Santiago de Chile, 1997.

Pérez, Gabriel Jaime, "Hacia un periodismo socialmente responsable", Signo y Pensamiento, No. 32, Universidad Javeriana de comunicación, Bogotá, 1998, pp. 91-98.

Rub-Mohl, Stphan, "Entrega de información medial a control remolo", en Thesing, J. y Hofmeister (editores), Medios de comunicación, democracia y poder, Fundación Konrad Adenauer, Argentina, 1995, pp. 103-124.

Sobrino, Jon, "El Espiritu de la verdad", Carta a las Iglesias, No. 409 y 410; Servicio Informativo del Centro Pastoral de la UCA, San Salvador, 1998.

Sobrino, Jon, El principio misericordia, San Salvador: UCA Editores, El Salvador, 1993, pp. 249-263.

UNESCO, Nuevo Código Internacional de Etica Periodistica, París, 1983.

Vidal, Marciano, Moral de actitudes. Moral social, Tomo 3, Sigueme, Salamanca, 1980. 